|| Print ISSN: 2589-7837 || Online ISSN: 2581-3935 ||

International Journal of Medical Science and Diagnosis Research (IJMSDR)

Available Online at www.ijmsdr.com

NLM (National Library of Medicine ID: 101738824)

Original Research Article

Volume 5, Issue 7; July:2021; Page No. 33-37

PRESCRIBING PATTERN OF DRUGS USED IN PAEDIATRIC PATIENTS IN OUTPATIENT DEPARTMENT OF A TERTIARY CARE INSTITUTION

\title{
Nitika Hans
}

MD Pharmacology, working as Senior Resident in department of Pharmacology, GMC Amritsar

\section{Conflicts of Interest: Nil}

Corresponding author: Nitika Hans

DOI: https://doi.org/10.32553/ijmsdr.v5i7.827

\begin{abstract}
:
Background: Paediatric prescription is a major concern in terms of public health since infections are the most frequent cause of childhood disease. The aim of this hospital-based observational prospective study was to assess the pattern of drug use in the paediatric outpatient department attached to government medical college, Amritsar.
\end{abstract}

Methods: A prospective study of six months duration was carried out for the month of October 2020 to March 2021. A total number of 201 patients case sheets were utilized for our study from paediatric outpatients department of GNDH, Amritsar. The data collected was then analysed for various prescribing indicators as laid down by world health organisation (WHO) for analysis of drug use parameters.

Results: The average number of drugs per encounter was 2.52 . In present study antibiotic were $18 \%$ of total drugs prescribed. Antihistaminics prescribed were $25 \%$. Syrup was the most prescribed dosage form. \%age of drugs prescribed from essential drugs list was 60.3\%. Polypharmacy was evident from the study.

Conclusions: Drug prescribing in children is relatively high in GNDH, Amritsar. This study revealed deviation in prescribing pattern from WHO core prescribing indicators. Possible reasons are heavy patient load, lack of essential drug list, insufficient government supply of generic drugs and lack of regular prescription audits.

Keywords: prescription pattern, observational study, Paediatric, WHO core prescribing indicators.

\section{Introduction:}

A prescription is a medico-legal document given by the prescriber to a patient to be handed over to pharmacist to dispense the medication. Rational prescription is very important to avoid Irrational prescribing which is a global problem. The rationality of prescribing pattern is of most importance because bad prescribing habits including misuse, overuse and underuse of medicines can lead to unsafe treatment, exacerbation of the disease, health hazards and economic burden on the patients and wastage of resources. Examples of irrational use of medicines include: poly-pharmacy, inadequate dosage, and use of antimicrobials even for nonbacterial infections, excessive use of injections when oral forms are available and inappropriate, self-medication and noncompliance to dosing regimes.(1)

Drug prescribing is a skill that needs to be refined on a continuing basis. It reflects that professional's skills and attitude toward diagnosis of an ailment and selection of appropriate treatment. In view of this, it is important to do study the pattern of prescribing in pediatrics patients on continuous bases.(2)

Prescribing pattern studies are powerful exploratory tools to ascertain the role of drugs in society. In a tertiary care centre, prescribing is expected to be judicious, appropriate, safe, effective and economical. (3) The ultimate goal is to achieve rational and effective medical care, 
particularly in the economically developing countries. This study is planned to analyze the prescribing pattern in pediatric outpatients attending at a tertiary care hospital. Paediatrics is the branch of medicine dealing with the development, diseases and disorders of children below 12 years. Infants and children are especially vulnerable to contact illnesses and to the harmful effect of drugs due to differences in pharmacodynamics and pharmacokinetics.(4) The study of prescribing patterns seeks to monitor, evaluate and if necessary suggest modifications in prescribing practices to make medical care rational and effective.(5)The assessment of drug utilization is important for clinical, educational and economical reasons and study focuses on effective medical treatment of pediatric patients with accurate diagnosis and selecting the proper drug regimens, avoiding unnecessary use of antibiotics and minimizes the prescription errors.

Drug prescription is an integral part of the provision of health .Irrational use of drugs leads to ineffective treatment, adverse effects and economic burden on both patients and society. Poor quality prescription writing increases the risk of serious medication errors. They are Error of omission And Error of commission

There is poor prescribing because there is no guidelines, ignorance, poor training, unco opeperative patient attitude and aggressive promotion of branded drugs.

The rational prescribing can be assessed by conducting prescription audits from time to time

Prescription analysis is required to quantify the medication error, to look for possible solutions and have effective utilization of the resources spent on drugs

The World Health Organization (WHO) developed the prescribing indicators to measure the rational usage of drugs in primary care and to assess the prescribing pattern of drugs.(6) The aim of the study was to assess the prescribing pattern of antibiotics in pediatric patients of Amritsar, Punjab, India.

\section{Objectives}

To analyze the prescribing pattern in pediatric outpatient department of a Tertiary Care Hospital

Generate data on the extent of rational/irrational prescribing.

\section{Methodology}

A prospective study over six months was conducted. 201 prescriptions were collected from Pediatric out-patient department attached to Govt. Medical College, Amritsar.

\section{Inclusion Criteria}

Prescriptions meant for children below 12 years

\section{Exclusion Criteria}

Prescriptions without information about the prescriber or patient

Prescriptions were analyzed for WHO core prescribing indicators that include average number of drugs in each encounter, percentage of drugs prescribed by generic names, percentage of encounters with an antibiotic prescribed, percentage of encounters with an injection prescribed and percentage of drugs prescribed from essential drug list. Commonly prescribed class of drugs include antihistaminics , antipyretics, antibiotics, vitamins / minerals, bronchodilators, steroids and others . Commonly prescribed dosage forms include syrup, tablet, drops, parenteral and ORS. Prescriptions were checked for any missing data whether drug dose, diagnosis, frequency of administration \& duration of therapy clearly mentioned and rational.

Statistical analysis: Descriptive statistical analysis was performed.

\section{Results}

Out of 301 prescriptions analyzed, 568 drugs were prescribed. Average number of drugs/prescription being 2.52 (range 1-6) and Male 100, female 201.

Table 1: WHO core prescribing indicators: 


\begin{tabular}{|l|l|}
\hline Average number of drugs per encounter & 2.52 \\
\hline \%age of drugs prescribed by generic name & 61.1 \\
\hline \%age of encounters with an antibiotic prescribed & 48.3 \\
\hline \%age of encounters with an injection prescribed & 6 \\
\hline \%age of drugs prescribed from essential drugs list & 60.3 \\
\hline
\end{tabular}
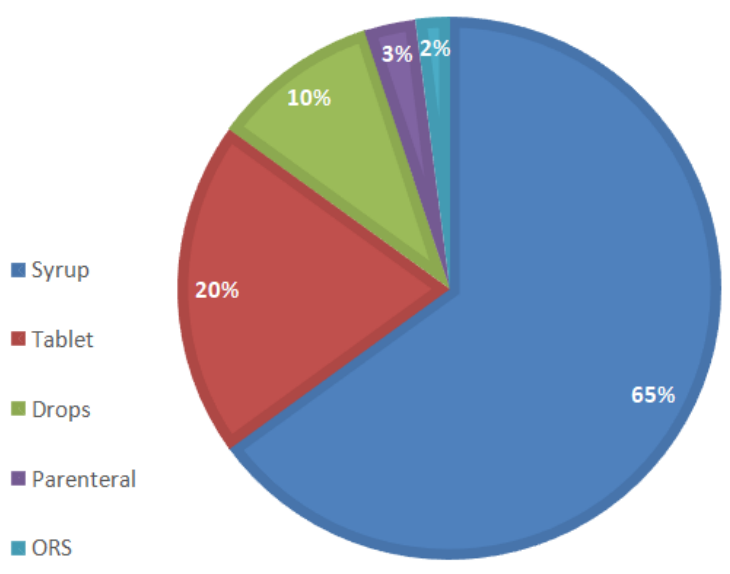

Figure 1: Commonly prescribed dosage forms (in percentage)

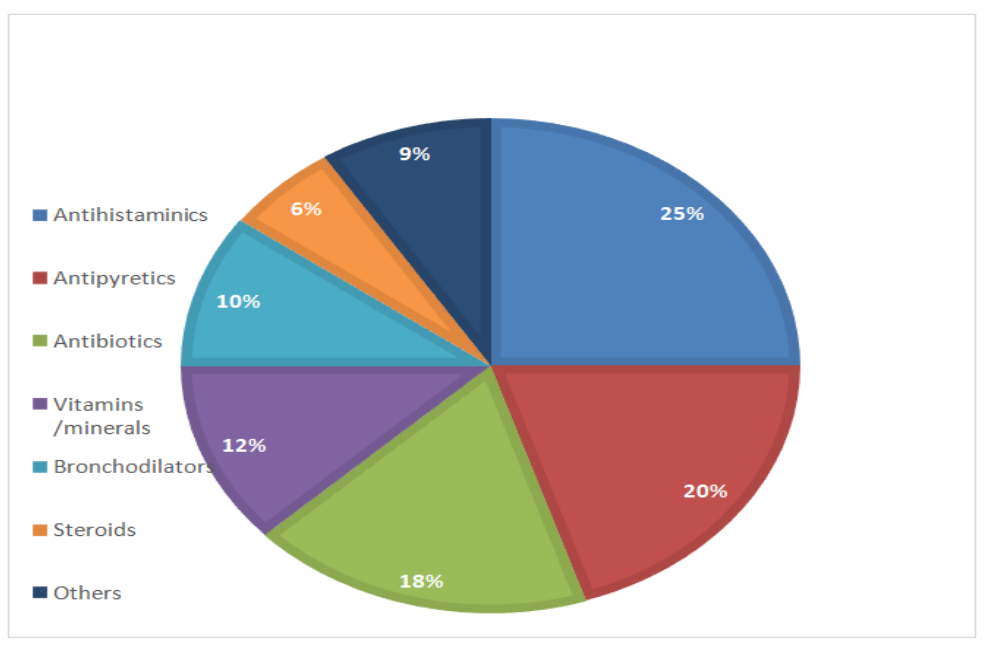

Figure 2: classes of drug prescribed (in percentage)

Table 2: Data missing in prescriptions

\begin{tabular}{|l|l|}
\hline Diagnosis of patient & $21 \%$ \\
\hline Duration of therapy & $13 \%$ \\
\hline Dose of drug & $5 \%$ \\
\hline Frequency of administration & $6 \%$ \\
\hline
\end{tabular}

\section{Discussion}


In study in Karachi, Pakistan, the number of male patients was more than females and the ratio was more than that expected from the sex ratio of Nepal (7). A similar result was observed in a previous study (8). In Venkateswaramurthy.N et al prospective observational study of paediatric outpatients was conducted on 354 patients. The demographic profile in this study showed male (57.9\%), female $(42.1 \%)$ proportion. This study indicated that males patients was comparatively more than the number of female patients coming for consultation. (9) In Shankar P.R. et al study the mean $( \pm \mathrm{SD})$ number of drugs prescribed was 4.5 ( \pm 3.7$)$.(10) This is less than the mean number of drugs prescribed in a previous study(8). Antibiotics were the most commonly-prescribed class of drugs and $70 \%$ of admissions were prescribed antibiotics. In eastern Nepal, it was observed that $84 \%$ of patients were prescribed an antimicrobial, and antimicrobials constituted $42.8 \%$ of the total drugs(11).

In Venkateswaramurthy.N et al study the most commonly used drug group was antibiotic. Other class of drugs such as NSAID's (14\%), bronchodilators $(13.9 \%)$, antiemitics (3.3\%), nasal decongestants $(3.4 \%)$, topical preparations $(8.6 \%)$, nutritional suppliments $(4.58 \%)$, gluco corticoids $(3.2 \%)$, proton pump inhibitors $(1.3 \%)$ , anti spasmodic (1.3\%), laxative and purgatives $(0.6 \%)$, anti diarrheals $(0.6 \%)$ and antihistamines $(0.74 \%)$ were prescribed. Similar study was conducted by Janaki torvi and suman et al (12) which shows out of 300 prescriptions $82 \%$ are antibiotics, $32 \%$ of antipyretics , $28 \%$ of antihistamines were prescribed. (9)

In Venkateswaramurthy. $\mathrm{N}$ et al study $85.6 \%$ of medications are oral medications, $4.4 \%$ of cases consist of inhalational drugs, $8.6 \%$ of case are topical drugs and $1.3 \%$ are suppositories or pesseries. Most of the drugs were given as in the form of tablet, capsule, suspension or solution. Gastro intestinal drugs were prescribed in the pattern of Proton pump inhibitor (18\%), Anti diarrheals (8.9\%), Laxatives (8.9\%) Antiemetics $(46.2 \%)$ and Antispasmodics (18\%). In Venkateswaramurthy. $\mathrm{N}$ et al study use of antimicrobial drugs is highest for children. Thus, there is an ample scope of improving the prescribing pattern by keeping the number of medicines as low as possible, prescribing medicines by generic names, using medicines appropriately after selecting and consciously keeping the cost of therapy low.(10)

In Shankar P.R. et al study $48.9 \%$ of the drugs were prescribed by the parenteral route. Antibiotics, intravenous fluids, antiepileptic drugs and drugs for bronchial asthma were commonlyprescribed parenterally. (10)As noted in a previous study,(13) the patients were usually discharged once the antibiotics were changed from the parenteral to the oral route. Previous studies in Nepal had reported that the proportion of antibiotics prescribed parenterally varied from $53.8 \%$ to $75 \%(8)$. In Shankar P.R. et al study, $61.7 \%$ of antibiotics were prescribed parenterally. The parenteral route may be necessary in paediatric patients but is more expensive in terms of nursing resources.(10) The number of drugs prescribed by generic name was low, and efforts must be made to encourage prescribing by generic names.

In D. Sharad Gedam study average number of drugs prescribed was 1.69 per prescription. Result is comparable to Dimri et al who have reported the average numbers of drugs prescribed to be $2.31 \& 2.81$ respectively. (14) In D. Sharad Gedam study $2.69 \%$ of medications were prescribe by generic names. In other studies conducted by mohanty et al found this as $1.42 \%$ \& Dimeri et al in Chandigarh as 5.8\%. A very fair number of drugs $(40 \%)$ were prescribed from national list of essential medicine 2011. Prescribing pattern in other studies include Dimri et al, Mohanty et al, Adebyo et al \& Bharty et al were $68 \%, 45 \%, 64 \%$ \& $58 \%$ respectively. 14 In D. Sharad Gedam study no injection were prescribed. In other studies conducted by Dimri et al \& Kumari et al it was $1.18 \%$ \& $1.17 \%$ respectively.14 In D. Sharad Gedam study prescribing percentage of antibiotics was $37.26 \%$. Other studies reported 18.5-29\% of antimicrobial use. Antipyretics are commonly prescribed drugs (44\% of total patient) Paracetamol was prescribed $37 \%$ of patient followed by Ibuprofen in $8.1 \%$. In 
D. Sharad Gedam study antihistaminics were prescribed in $29.07 \%$ of patient. Most number of the drugs was prescribed by oral route $(99.32 \%)$ which is followed by nasal $(0.68 \%)$. The most commonly medicine dosage form has syrup $(62.19 \%)$ followed by drops $(13.87 \%)$ compared to tablet $(6.9 \%)$.

\section{Conclusion}

Prescription audits are useful in quantifying medication errors and predicting rational drug use.This study revealed deviation in prescribing pattern from WHO core prescribing indicators. Possible reasons are heavy patient load, lack of essential drug list, insufficient government supply of generic drugs and lack of regular prescription audits. There is a scope for improvement in prescribing patterns in areas of writing generic names of drugs, essential drugs, writing legible and complete prescription

\section{Bibliography}

1. Abidi A, Gupta S, Kansal S, Ramgopal. Prescription auditing and drug utilization pattern in a tertiary care teaching hospital of western UP. Int J Basic Clin Pharmacol. 2012 Dec;1(3):184-90.

2. Pramil T, Rajiv A, Gaurav G. Pattern of prescribing at a pediatric outpatient setting in northern India. Indian Journal of Pharmacy Practice, 2012;Jan-Mar;5(1):404.

3. Summers RS, summers B. drug prescribing in paediatrics. Ann trop paediatrics. 1986; 6(2): 129-33.

4. Peter G, Micheal DR. Principles of Drug Therapy. In: Kliegman, Behrman, Jenson, Stanton, editors. Nelson Text book of Pediatrics. 18thedn. Vol 1. Philadelphia: Saunders Elsevier; 2007. p. 331-2.

5. World Health Organization. How to Investigate Drug Use in Health
Facilities: Selected Drug use

Indicators. Geneva: WHO. Available from:

http://www.apps.who.int/medicinedocs/pd f/se/ se.pdf.

6. Central Bureau of Statistics. Population Monograph of Nepal. Volume 1. Kathmandu: Central Bureau of Statistics, 2003.

7. Palikhe N. Prescribing pattern of antibiotics in paediatric hospitals in Kathmandu valley. Kathmandu Univ Med J 2004; 2:6-12.

8. Venkateswaramurthy.N et al . Assessment of Drug Prescription Pattern In Paediatric Patients. J. Pharm. Sci. \& Res. Vol. 9(2), 2017, 81-84

9. Shankar P.R. et al .Prescribing patterns among paediatric inpatients in a teaching hospital in western Nepal. Singapore Med J 2006; 47(4) : 265

10. Rehana HS, Naga Rani MA. A study on the drug prescribing pattern and use of antimicrobial agents at a tertiary care teaching hospital in eastern Nepal. Indian $\mathbf{J}$ Pharmacol 1998; 30:175-8

11. Janaki R, Torvi Suman, Dambal. Drug prescription pattern in paediatric out patient clinic in a tertiary hospital. International Journal of Medical Research. 2011;15:1220.

12. Shankar PR, Partha P, Shenoy NK, et al. Prescribing patterns of antibiotics and sensitivity patterns of common microorganisms in the Internal Medicine ward of a teaching hospital in Western Nepal: a prospective study. Ann Clin Microbiol Antimicrob 2003;2:7.

13. Dimri S, Tiwari P, Basu S, Parmar VR. Drug use pattern in children at a teaching hospital. Indian Pediatr. 46(2):2009; 165-7. 